\title{
Lo necrológico en la producción científica de la Dra. Rosario Camacho Martínez
}

Francisco José Rodríguez Marín

Universidad de Málaga

El interés de Rosario Camacho por la multiplicidad de mensajes y la cultura simbólica de carácter funerario fue, inicialmente, una consecuencia natural de sus investigaciones sobre la arquitectura barroca. En uno de sus libros más reconocidos, Málaga barroca. Arquitectura religiosa de los siglos XVII y XVIII (1981) analizó el panteón de los condes de Buenavista en la iglesia del monasterio de la Victoria y su impresionante conjunto de relieves y esculturas en torno a la muerte, recogiendo algunas de las interpretaciones que hasta entonces se habían realizado, como las de Juan Temboury o Santiago Sebastián.

El carácter excepcional del conjunto arquitectónico de la iglesia, el monasterio, y especialmente, de la rica y original superposición de espacios verticales integrado por el mencionado panteón, la sacristía y el camarín de la Virgen, justifican la atención pormenorizada que se le prestó en una de las carpetas que, incluyendo planimetría y dedicadas al Barroco, fueron publicadas por el Colegio de Arquitectos de Málaga. La titulada El Santuario de la Victoria de Málaga (1986) tuvo por au-

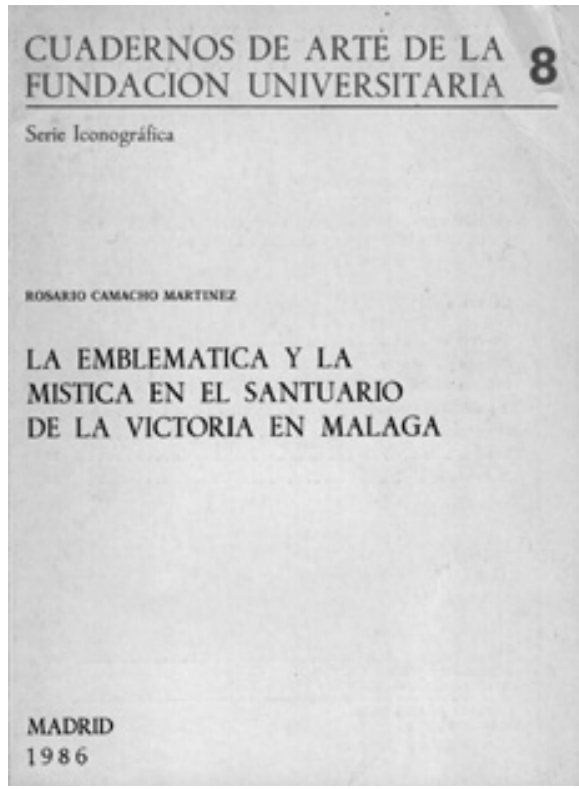

tores a Rosario Camacho y al arquitecto José María Romero.

Sin embargo, aunque los valores de este espacio los difundió en diversas obras de carácter divulgativo (Guía Artística de Málaga y su provincia vol. II [2006]; Guía Histórico Artística de Málaga [1992, 1997 y 2006], "Mecenazgo de los Condes de Buenavista. El convento de la Victoria de Málaga», La Universidad y nuestros mayores [2005]...), el análisis más completo fue 
el realizado en su obra La Emblemática y la Mística en el Santuario de la Victoria de Málaga (1986), publicada por la Fundación Universitaria Española dentro de la colección Cuadernos de Arte de la Fundación Universitaria, en la que ocupa el número 8.

Se trata de un opúsculo de tamaño reducido, pero en el que se aborda el tema con una gran densidad de contenido, que incide especialmente en las fuentes literarias y los libros de emblemas de la época que pudieron utilizarse para la configuración de su rico y polivalente programa iconográfico. Las guías espirituales coetáneas, como los ejercicios ignacianos o el Discurso de la Verdad de Miguel de Mañara aportan nueva luz interpretativa, mientras que conocidos repertorios como la Iconología de Cesare Ripa o los libros de emblemas de Covarrubias, Juan de Borja o el Pía Desideria de Hugo Hermann, nos sugieren cuales pudieron ser los referentes formales y morales, permitiendo elaborar una interpretación en clave culta de este espacio funerario.

Un papel similar al de la Victoria desempeñó la investigación realizada sobre la cripta de la iglesia de San Lázaro de Málaga, y vertida en la publicación titulada "Ciencia y mito en una imagen macabra: la cripta del hospital de San Lázaro de Málaga», que inicialmente fue una de las conferencias del congreso titulado La Literatura en las Artes, que organizó el ya desapareci- do Instituto de Estudios Iconográficos Ephialte. Las mejores aportaciones fueron publicadas en la colección Lecturas de Historia del Arte, que coordinó su director, el experto en iconografía Jesús M. ${ }^{a}$ González de Zárate, catedrático de la UPV.

El trabajo de Rosario Camacho fue publicado en el vol. II (Vitoria, 1990), y en él se analizan las macabras pinturas de su repertorio identificándose a las Parcas y a Cronos-Saturno portando el reloj de arena, pero también se señala a libros de anatomía, como el de Andrés Vesalio, como posible fuente de inspiración para la representación de las figuras en transición entre la vida y la muerte, tradicionalmente identificadas como leprosos. Prueba de lo acertado de esta interpretación es el hecho de las numerosas citas a este trabajo en publicaciones de otros autores editadas en idiomas diferentes al español, lo que confirma su trascendencia científica.

También tuvieron carácter funerario las capillas del claustro del monasterio de la Victoria, que ostentan una decoración pictórica recientemente restaurada y que fue analizada en el artículo titulado "Imagen y color recuperados en el Convento de Nuestra Señora de la Victoria de Málaga», publicado en el n. ${ }^{\circ} 24$ de la revista Boletín de Arte (2003), del que Rosario Camacho ha sido directora durante muchos años. Dentro de esta temática la última 
aportación, en sentido cronológico, ha sido la conferencia titulada "Lo necrológico en los programas iconográficos del santuario de la Victoria y la cripta de San Lázaro", con la que participó en las I Jornadas sobre Cementerios Patrimoniales. La muerte en la historia, el arte y la arqueología, celebradas en la Universidad de Málaga en el 2012 y cuyas actas estarán ya publicadas cuando estas líneas vean la luz. En este nuevo trabajo se matiza y madura el análisis de como el lenguaje emblemático se tradujo a aspectos formales en estos dos destacados espacios funerarios.

Fruto de la sensibilidad patrimonial de Rosario Camacho y su apertura intelectual respecto a nuevas modalidades patrimoniales es también su preocupación sobre el arte funerario contemporáneo presente en nuestros cementerios, sobre los que ha realizado una eficaz labor de defensa y reivindicación a través de instituciones y su participación en mesas redondas, como las celebradas en torno al cementerio de San Miguel (1995) y el Cementerio Inglés (1998), ambos de Málaga.

En el plano académico debe destacarse la publicación de "Moradas de la muerte en la Málaga contemporánea", trabajo presentado como contribución a I Encuentro Internacional sobre los Cementerios Contemporáneos. Una Arquitectura para la muer- te, celebrado en Sevilla en 1991 y que vio la luz dos años más tarde en una cuidada edición de la COPT de la Junta de Andalucía. Entre los aspectos más interesantes de esta investigación resalta la contextualización histórica del origen de los cementerios a partir de la R.C. de 1787 y la remisión a textos y ediciones de la época que aportan los razonamientos y argumentaciones de destacados ilustrados, no conocidos hasta el momento. Respecto a la ciudad de Málaga aporta una completa visión diacrónica de sus diferentes espacios de enterramiento, desde sus inicios hasta el siglo $\mathrm{XX}$, dando con ello paso a la arquitectura y urbanismo contemporáneos.

El monumental mausoleo de la familia Heredia en el cementerio de San Miguel obtuvo una atención pormenorizada en una publicación poco conocida, «El panteón de los Heredia en el Cementerio de San Miguel de Málaga", incluido en el número 1 del Boletín de la Asociación de Amigos (Málaga, 1999) constituida en torno a la defensa de esta necrópolis. En ella se aborda la génesis constructiva del edificio, la importancia que esta familia desempeñó en la Málaga del siglo XIX y se acomete una acertada interpretación de la simbología funeraria del edificio y el monumento sepulcral custodiado en su interior. 